Síntese de Peptídeos em Ambiente Pré-Biótico: Implicações para a Evolução Química

\author{
Escobar, C. C.;* Campo, L. F.
}

Rev. Virtual Quim., 2013, 5 (2), 179-187. Data de publicação na Web: 29 de março de 2013

http://www.uff.br/rvq

\title{
Synthesis of Peptides in Prebiotic Environment: Implications for the Chemical Evolution
}

\begin{abstract}
Since Miller's experiment in 1951, research on prebiotic chemistry has received much attention of chemists. However, there are a few lines of research with the focus directed to this science in Brazil. Therefore, the objective of this paper is to describe some of the research in this field, with emphasis on peptide synthesis under prebiotic conditions and the implication of these studies in the context of molecular enrichment on the primitive earth. We also want to encourage new researchers conducting research in this area as well as promoting scientific debate related to the topic of the origin of life.
\end{abstract}

Keywords: Prebiotic chemisty; peptides; astrobiology in Brazil.

\section{Resumo}

Desde o experimento de Miller em 1951, a pesquisa em química pré-biótica tem recebido muita atenção dos químicos. No entanto, existem poucas linhas de pesquisa com o enfoque direcionado a esta ciência no Brasil. Assim, o objetivo deste artigo foi descrever algumas das pesquisas neste campo, com ênfase na síntese de peptídeos em condições pré-bióticas e a implicação destes estudos no contexto do enriquecimento molecular na terra primitiva. Desta forma, pretende-se incentivar novos pesquisadores a desenvolver pesquisas nesta área, bem como promover o debate científico relacionado com o tema da origem da vida.

Palavras-chave: Química pré-biótica; peptídeos; astrobiologia no Brasil.

\footnotetext{
* Universidade Federal do Rio Grande do Sul, Departamento de Engenharia Química, R. Eng. Luis Englert, s/n. Campus Central, CEP 90040-040, Porto Alegre-RS, Brasil.

$M$ cicero.escobar@gmail.com DOI: $10.5935 / 1984-6835.20130020$
} 


\title{
Síntese de Peptídeos em Ambiente Pré-Biótico: Implicações para a Evolução Química
}

\author{
Cicero C. de Escobar, ${ }^{a, *}$ Leandra F. Campo ${ }^{b}$ \\ ${ }^{a}$ Universidade Federal do Rio Grande do Sul, Departamento de Engenharia Química, R. Eng. \\ Luis Englert, s/n. Campus Central, CEP 90040-040, Porto Alegre-RS, Brasil.

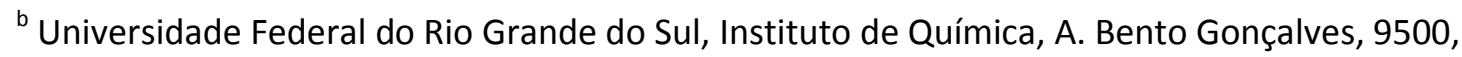 \\ CEP 91501-970, Porto Alegre-RS, Brasil. \\ * cicero.escobar@gmail.com
}

Recebido em 10 de setembro de 2012. Aceito para publicação em 4 de março de 2013

\section{Introdução}

2. Síntese de peptídeos em ambiente pré-biótico

3. Implicações para a evolução química

\section{Conclusões}

\section{Introdução}

Historicamente, a química pré-biótica, como ciência experimental, começou a partir do experimento de Miller. ${ }^{1} \mathrm{Na}$ tentativa de simular o ambiente atmosférico da terra primordial, foram confinados, em um sistema fechado, componentes que caracterizavam um ambiente redutor, constituído de $\mathrm{H}_{2} \mathrm{O}$, $\mathrm{NH}_{3}, \mathrm{CH}_{4}$ e $\mathrm{H}_{2}$. Após o sistema sofrer descargas elétricas, foram obtidos os aminoácidos glicina, $\alpha$-alanina, e $\beta$-alanina, ácido aspártico e $\alpha$-aminoácido n-butírico.

Há diversas hipóteses para o cenário prébiótico que tentam explorar as evoluções químicas das moléculas na Terra primordial. ${ }^{2,3} \mathrm{O}$ entendimento dessa evolução perpassa por compreender uma das maiores barreiras existentes - em função do que sabemos do funcionamento das células: 0 ADN carrega toda a informação para sintetizar proteínas, porém é fortemente dependente desta última para catalisar reações biológicas. ${ }^{4}$ Isso conduz ao problema "ovo-galinha": o que surgiu primeiro, o metabolismo ou a genética? ${ }^{5,6}$

Conforme é possível observar na Figura 1, os nucleotídeos são moléculas mais complexas que os aminoácidos. As células modernas utilizam o ADN como molécula informacional. Entretanto, no contexto de química pré-biótica, os proponentes de que o código genético apareceu primeiro defendem o papel do ARN, e não do ADN, como molécula informacional, o que acabou tornando-se conhecido como o mundoARN. ${ }^{7,8}$ Esta proposta se fortaleceu com a descoberta de que as moléculas de ARN possuem propriedades catalíticas; sendo assim, poderiam atuar duplamente, ou seja, com o papel de enzimas e de moléculas replicadoras. ${ }^{9}$ Porém, a hipótese do mundo$A R N$ recebe críticas, sobretudo porque (i) o 
grupo fosfato, quando em solução, sofre precipitação instantânea na presença de cátions divalentes $\left(\mathrm{Ca}^{+2}\right) ;^{10}$ (ii) mesmo que os três blocos de construção do ARN (ribose, nucleobase e fosfato) estivessem disponíveis na Terra primordial, sua auto-organização e polimerização com a correta regiosseletividade dificilmente seria alcançada por síntese ${ }^{11,12}$ e (iii) não revela como as primeiras moléculas de ARN foram formadas a partir de cadeias pequenas de polinucleotídeos que, na melhor das hipóteses, tiveram propriedades catalíticas fracas. ${ }^{13}$
A<smiles>NCC(=O)O</smiles><smiles>Nc1ncnc2[nH]cnc12</smiles>

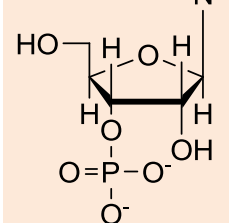

O-<smiles>Nc1ccn(C2OC(CO)C3OP(=O)(O)OC2C3O)c(=O)n1</smiles>

\section{B}<smiles>CC(N)C(=O)O</smiles>

D<smiles>Cn1cnc2c(=O)[nH][nH]c21</smiles><smiles>O[14CH2]O[14CH2]O</smiles><smiles>OC1[C@H]2C[C@H]1[C@H](O)O2</smiles><smiles>[O]OP[O-]</smiles><smiles>[O-]</smiles>

$\mathbf{F}$<smiles></smiles>

$\mathrm{HO}$

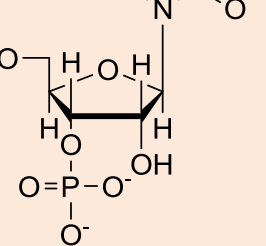

Figura 1. Moléculas de aminoácidos (A: Glicina, B: Alanina) e nucleotídeos do ARN (C: Adenina, D: guanina, E: Citosina, F: Uracila)

Os defensores de que o metabolismo antecede o código genético na evolução química consideram os peptídeos como as primeiras moléculas a exibirem-se em organizações moleculares que permitiram o aparecimento da vida. ${ }^{10,14,15}$ A partir do conhecimento do funcionamento da célula, sabe-se que as proteínas são os catalisadores das reações bioquímicas. Sendo assim, os peptídeos se tornam candidatos de destaque na evolução molecular na Terra primordial. ${ }^{13}$ Além disso, estudos teóricos ${ }^{16}$ sugerem que um conjunto de 10 aminoácidos é mais tolerante a erros e mais apropriado para uma evolução gradativa cada vez mais complexa do que um conjunto de 4 diferentes nucleobases. Entretanto, o problema dessa hipótese, ao contrário do mundo- $A R N$, é que ela não indica um caminho claro para a replicação e preservação da informação, funcionalidade necessária para a evolução biológica. ${ }^{13}$ Além disso, a formação de peptídeos a partir dos aminoácidos constituintes enfrenta a dificuldade de ser cineticamente e termodinamicamente desfavorável, sobretudo em solução aquosa. ${ }^{4,10}$

Uma vez reconhecidas às possibilidades e as limitações desses dois cenários, foi proposto uma terceira alternativa, na qual ocorre a existência de uma coevolução. Este 
modelo sugere a colaboração mútua no mesmo ambiente pré-biótico - auxiliando para o enriquecimento molecular -, entre peptídeos e oligonucleotídeos. ${ }^{17,18}$ Nesse contexto, estudos mostram a possibilidade de formação simultânea de peptídeos e oligonucleotídeos em temperatura ambiente. ${ }^{19-21}$

Atualmente, os estudos de química prébiótica estão inseridos no contexto da astrobiologia. Nesta área do conhecimento, diversas abordagens científicas estão sendo feitas com o intento de estudar a origem, evolução, distribuição e destino da vida no universo. ${ }^{22}$ A comunidade científica brasileira tem demonstrado interesse em institucionalizar a astrobiologia no país; recentemente, o Brasil foi associado ao NAI (NASA Astrobiology Institute). ${ }^{23}$ Além disso, conforme discutido por Fabio Rodrigues e colaboradores, ${ }^{24}$ atualmente há pesquisadores envolvidos com a pesquisa em química pré-biótica no país. Entretanto, esta área do conhecimento ainda é pouco explorada por pesquisadores no Brasil.

Nesse sentido, o presente trabalho tem como objetivo a divulgação de alguns dos principais experimentos de produção de peptídeos em ambiente pré-biótico. Nele, discutisse as implicações dessas sínteses, do ponto de vista químico, em cenários nos quais o mundo peptídeo tem sido defendido como uma alternativa ao mundo-ARN, ou como participante de uma coevolução química. Sendo assim, pretende-se incentivar novos pesquisadores a desenvolver pesquisas nesta área, bem como promover o debate científico relacionado com o tema da origem da vida.

\section{Síntese de peptídeos em ambiente pré-biótico}

Poucos anos após o experimento de Miller, evidências de síntese de peptídeos começaram a aparecer. Com o objetivo de superar as dificuldades termodinâmicas e cinéticas, alguns caminhos de síntese começaram a ser propostos. Os primeiros experimentos realizados consistiram em polimerização térmica de um aminoácido em condições anidras na faixa de 180 으, nos quais foi possível a obtenção de copolímeros. ${ }^{25}$ Entretanto, constatou-se que os produtos provenientes desse tipo de reação eram majoritariamente do tipo $\beta$ - e não $\alpha$-como ocorre na maioria das proteínas atuais. ${ }^{26}$ Outro tipo particular de reação com agentes de condensação foi investigado por diversos autores. Alguns destes agentes testados foram os cianatos, ${ }^{27}$ trimetafosfatos $^{28}$ e cianamidas. $^{29}$ Nestas condições de síntese, os autores mostraram que os peptídeos poderiam ter sido formados sem a mediação de ácidos nucleicos. ${ }^{29}$ Contudo, alguns autores ${ }^{26}$ argumentaram que o produto destas reações pouco se assemelha com as proteínas biológicas. Além disso, a concentração requerida dos agentes de condensação torna implausível a existência deste tipo de reação em ambiente pré-biótico., ${ }^{7,8}$

Uma provável dificuldade durante a síntese de biomoléculas em lagos e lagoas na Terra primitiva foi à elevada diluição desses compostos, dificultando a interação adequada para as reações químicas. Nesse sentido, Wächtershäuser ${ }^{30}$ sugere que compostos orgânicos puderam ter sido fixados em uma superfície cristalina, como no caso dos cristais de pirita. $\mathrm{O}$ autor se refere a uma possibilidade de origem da vida autotrófica, na qual a pirita poderia ter atuado como fonte de energia na produção de biomoléculas, como os peptídeos. Após a publicação dessa hipótese, trabalhos experimentais foram conduzidos. Entre alguns desses, destaca-se o de Huber e Wächtershäuser, ${ }^{31}$ no qual mostram a formação de peptídeos sob condições que simulam ambientes hidrotermais. Em sistemas aquosos a 100 o $\mathrm{C} \mathrm{e} \mathrm{pH}$ entre 7-10 contendo sulfeto de níquel ( $\mathrm{NiS}$ ) e sulfeto de ferro (FeS) em reações do tipo slurry, juntamente com monóxido de carbono (CO) dissolvido em água e sulfeto de hidrogênio $\left(\mathrm{H}_{2} \mathrm{~S}\right)$ ou metanotiol $\left(\mathrm{CH}_{3} \mathrm{SH}\right)$ como agentes de 
condensação, foram formados dipeptídeos a partir dos aminoácidos de fenilalanina, glicina e tirosina. $\mathrm{O}$ trabalho, além de demonstrar a versatilidade de cenários possíveis para síntese de peptídeos, apoia a hipótese da origem da vida em condições termofílicas. ${ }^{31}$

Ciclos de hidratação-desidratação também foram investigados como condições pré-bióticas. Através destes ciclos, é possível simular o efeito das chuvas ou marés (hidratação), bem como o efeito do calor do sol (desidratação) provocando a evaporação da água a ponto de deixar ambientes totalmente secos. Após determinado tempo, lagoas são formadas novamente por chuvas ou marés e, outra vez, pelo efeito do calor do sol são desidratadas e secas. Lahav e colaboradores $^{32}$ compararam a quantidade de oligômeros de glicina formada entre experimentos com e sem a presença de ciclos de hidratação-desidratação. Os autores concluíram que a presença destes ciclos aumenta consideravelmente $o$ rendimento de produção de oligômeros, sendo este valor tanto maior conforme o aumento do número de ciclos.

Bernal $^{33}$ foi o primeiro a sugerir que os minerais tiveram relevância no ambiente prébiótico ao interagir com determinadas moléculas orgânicas. Desde então, diversos autores têm explorado os mecanismos desta interação. ${ }^{34,35}$ Estes minerais, sobretudo as argilas, têm a capacidade de: ${ }^{36}$ i) adsorver monômeros (aminoácidos ou ácidos nucleicos) e, consequentemente, aumentar a concentração destes de forma a ter maior disponibilidade para reagir; ii) facilitar a condensação e polimerização destes monômeros; e iii) oferecer uma superfície com capacidade de adsorção específica para cada biomolécula. Além da argila, foram investigados minerais como a caulinita e a montmorilonita. ${ }^{37,38}$ Além destes, a sílica e a alumina também se mostraram eficientes para concentrar e promover o crescimento da cadeia carbônica a partir de aminoácidos. ${ }^{39,40}$ Recentemente, minerais de óxido de ferro também foram investigados. ${ }^{41}$
Em outros estudos, a interação dos aminoácidos com minerais mostraram a possibilidade de formação de heteropeptídeos. ${ }^{42,43}$

No final dos anos 80, foi proposta outra rota de produção de peptídeos sem a presença de minerais. ${ }^{44,45}$ A formação de peptídeos induzida por sais, ou SIPF (do inglês Salt-Induced Peptide Formation) foi inicialmente testada com solução de glicina aquecida a 85 o C (a partir de um dia até três semanas) em presença de cátions $\left(\mathrm{Mg}^{+2}, \mathrm{Ca}^{+2}\right.$, $\mathrm{Cr}^{+3}, \mathrm{Mn}^{+2}, \mathrm{Co}^{+2}, \mathrm{Ni}^{+2}, \mathrm{Cu}^{+2}, \mathrm{Zn}^{+2}, \mathrm{Cd}^{+2}, \mathrm{Al}^{+3}$, $\mathrm{Fe}^{+2}$ e $\mathrm{Mo}^{+6}$ ). O cobre favoreceu a formação de oligopeptídeos de glicina desde que a concentração de cloreto de sódio não ultrapassasse $3 \mathrm{~mol} / \mathrm{L}$, esquematicamente apresentado na Figura 2. Os experimentos foram realizados em presença de $\mathrm{NaCl}$, tendo em vista que a sua existência na Terra primordial é apontada como sendo similar ou superior a concentração deste sal nos oceanos na atualidade (500 mM); e argumentos que sugerem a presença de cobre também têm sido defendidos. ${ }^{46,47} \mathrm{O}$ rendimento dos peptídeos formados depende da concentração de aminoácido inicial e da relação molar entre o aminoácido e o cobre, sendo esta, na maior parte dos testes, mais eficiente quando utilizado na proporção de 2:1. ${ }^{10}$ Com base nos resultados otimistas dos autores que estudaram as reações do tipo SIPF, foram propostos experimentos que combinassem diferentes minerais no meio de reação. Na presença de minerais como montmorilonita ou hectorita, Rode e colaboradores ${ }^{48}$ obtiveram peptídeos a partir de (i) diglicina $(\mathrm{Gly})_{2}$ ou uma mistura de glicina (Gly) e diglicina (Gly) ${ }_{2}$ e a partir de (ii) uma mistura de dialanina (Ala $)_{2}$ e alanina (Ala). Na maioria dos casos, os rendimentos obtidos de alguns produtos como $(\mathrm{Gly})_{5}$, $(\text { Gly })_{6}, \quad(\mathrm{Ala})_{3}, \quad(\mathrm{Ala})_{4}$ e $(\mathrm{Gly})_{6} /(\mathrm{Gly})_{3}$ foram superiores do que quando da ausência do mineral. A partir destes experimentos, podese supor que as reações do tipo SIPF combinados com minerais são compatíveis. ${ }^{49}$ 


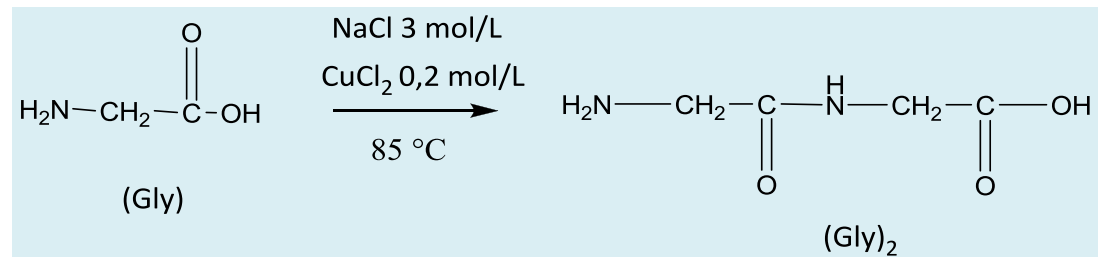

Figura 2. Representação de sistema químico para produção de oligopeptídeos segundo os experimentos de Schwendiger e Rode ${ }^{44}$

\section{Implicações para a evolução química}

O acúmulo de evidências sobre a síntese pré-biótica de peptídeos têm possibilitado aos cientistas proporem cenários de evolução molecular nos quais essas biomoléculas assumem o papel central ou estão inseridas em um contexto de coevolução em conjunto com os oligonucleotídeos. A seguir pretendese discorrer acerca de algumas implicações da presença de peptídeos no contexto da química pré-biótica.

Uma implicação imediata da presença de peptídeos no ambiente pré-biótico pode estar relacionada com a possibilidade destes em atuarem como catalisadores na síntese de outros peptídeos, mesmo aqueles com cadeias carbônicas pequenas. ${ }^{50}$ Suwannachot e Rode ${ }^{51}$ realizaram experimentos do tipo SIPF através dos quais foi possível obter, em presença da glicina, um aumento de até 50 vezes na formação do dímero da alanina. Em outro trabalho recente, Gorlero e colaboradores $^{52}$ mostraram que dímeros ou trímeros da glicina são capazes de atuarem como catalisadores na condensação de peptídeos.

Conforme discutido por Lee e colaboradores, $^{53}$ outra característica importante dos peptídeos é sua capacidade de autorreplicação ou autocatálise. Nesse tipo de reação, um peptídeo pode atuar como catalisador em sua própria reação de síntese. Com o objetivo de testar a hipótese de peptídeos autorreplicantes, os autores demonstraram a atuação autocatalítica de um peptídeo de 32 aminoácidos ao acelerar a condensação e consequente formação da ligação peptídica entre um fragmento de 15 e outro de 17 aminoácidos, para dar origem ao mesmo peptídeo de 32 aminoácidos.

$\mathrm{Na}$ tentativa de entender como os primeiros organismos mais simples começaram a existir, muitos pesquisadores têm interesse no estudo do encapsulamento do material genético no interior de vesículas, sendo que a auto-organização destas é um dos componentes principais do que se acredita ser necessário para a existência de células primitivas. ${ }^{54,55}$ Nesse sentido, a possibilidade de formar moléculas autoorganizadas é uma das consequências mais importantes advindas da síntese de peptídeos e esse processo pode ter desempenhando um papel central na formação das primeiras protocélulas. ${ }^{56} \mathrm{~A}$ auto-organização de peptídeos ocorre naturalmente nas células modernas, como por exemplo, na formação de amiloides, os quais podem depositar-se em vários tecidos, colaborando para a causa de doenças como Alzheimer, Parkinson e diabete do tipo II. ${ }^{57,58}$ Apesar das células modernas possuírem uma membrana fosfolipídica, alguns autores defendem que poderia ter sido baixa a probabilidade que estas estivessem disponíveis na Terra primordial nos mesmos locais que os peptídeos e os oligonucleotídeos. ${ }^{13}$ Outra consideração desfavorável para a existência das membranas fosfolipídicas na Terra primordial está associada à sua baixa permeabilidade para moléculas polares e iônicas; ${ }^{59}$ células modernas superam essa dificuldade com um sistema de transporte complexo de proteínas. Diversos autores sugerem a existência da auto-organização de peptídeos 
em algum estágio durante a origem da vida. $^{26,60-63}$ Recentes trabalhos ${ }^{16,63}$ sugerem que em determinado estágio de evolução molecular, os peptídeos seriam capazes de passar por um processo de coevolução com a participação de oligonucleotídeos e, desta forma, poderiam se auto-organizar em vesículas. Estas, por sua vez, atuariam como uma espécie de proteção aos oligonucleotídeos, ou seja, encapsulando-os através de uma membrana semipermeável primitiva. Recentemente, Ohad e Gazit ${ }^{60}$ publicaram resultados de experimentos nos quais, após a formação de dímeros de fenilalanina, seguido de auto-organização espontânea dos mesmos, foi possível compartimentar e estabilizar nucleotídeos (adenosisa e diadenosina) nos arranjos supramoleculares do dímero da fenilalanina. Esse modelo de coevolução entre peptídeos curtos e fragmentos de ARN poderia ter servido como início para uma condição plausível de enriquecimento molecular.

As biomoléculas presentes nos organismos da Terra são homoquirais: proteínas contêm ácidos quase exclusivamente derivados de L-aminoácidos, enquanto que apenas $D$-açúcares aparecem nas moléculas ARN e ADN; e o mecanismo por trás dessa assimetria fundamental da vida permanece um problema em aberto. ${ }^{64}$ Nesse sentido, estudos teóricos sugerem que a autorreplicação de peptídeos pode ter causado uma amplificação de moléculas homoquirais. ${ }^{65}$ Considerando a existência de isômeros $L$ de de-peptídeos (Gly-Ala, Ala-Ala, Val-Val, Ala-Gly, Gly-Pro, entre outros) no ambiente aquoso pré-biótico, Weber e Pizzarello ${ }^{66}$ mostraram que partindo-se do glicoaldeído, estes peptídeos foram capazes de catalisar a síntese de tetroses com orientação estereoespecífica, preferencialmente na forma $D$. Os melhores resultados foram conseguidos na síntese da eritrose, na qual a presença do peptídeo ValVal forneceu mais de $80 \%$ em excesso enantiomérico. As reações do tipo SIPF auxiliam o entendimento da questão da homoquiralidade. Estas reações mostram uma preferência estereoespecífica a favor da forma $\mathrm{L}$ de alguns aminoácidos. ${ }^{10}$
Experimentos partindo de L-alanina obtiveram rendimentos de dialanina em torno de $10 \%$ superior de D-alanina sob várias condições iniciais e tempos de reação. $^{67}$

Outra implicação que relaciona as reações do tipo SIPF com a evolução molecular diz respeito à bioquímica da vida. Os produtos dessa reação apresentam uma preferência específica de sequência dos aminoácidos que coincidem com as sequências de proteínas das membranas dos organismos do domínio archaea; aparentemente, essa correspondência é pouco provável que seja somente por acaso. ${ }^{68}$ Considerando que estes organismos são conhecidos como os mais antigos existentes na Terra, essa correspondência parece sugerir uma "impressão digital" de reações que geraram os primeiros peptídeos de cadeias longas e, em seguida, as proteínas. ${ }^{69}$

\section{Conclusões}

Ainda que não exaustivo, em vista da vasta literatura desta área, o presente trabalho apresentou alguns dos principais cenários experimentais que visam à obtenção de peptídeos em ambientes que simulam a Terra primordial. As principais propostas se baseiam na presença de ciclos de hidrataçãodesidratação, a participação de minerais e sais inorgânicos.

Os experimentos, ao longo dos últimos 60 anos, mostram que as simulações em laboratório podem ser úteis em esclarecer alguns aspectos da evolução molecular. Questões como a origem da homoquiralidade, a síntese de açúcares e o aparecimento de membranas primitivas, são alvos de pesquisa que estão intrinsecamente atreladas ao estudo da síntese de peptídeos em ambiente pré-biótico.

Em virtude dos experimentos comentados neste artigo, a possibilidade das proteínas serem antecessoras aos nucleotídeos na Terra primordial, ou ainda como participantes de uma coevolução, recebeu a 
atenção dos químicos. Portanto, pesquisas futuras ainda devem ser realizadas com o objetivo de tentar esclarecer melhor os caminhos percorridos pela evolução molecular até o aparecimento dos primeiros seres vivos. Espera-se, assim, que o debate científico acerca da origem da vida possa ser ampliado de modo que futuros pesquisadores brasileiros interessados no tema desenvolvam pesquisas na área de química pré-biótica.

\section{Referências Bibliográficas}

${ }^{1}$ Miller, S. L. Science 1951, 117, 528. [CrossRef] [PubMed]

${ }^{2}$ Zaia; D. A. Quím. Nova 2008, 31, 1599. [CrossRef]

${ }^{3}$ Peretó; J. Int. Microbiol. 2005, 8, 23. [Link]

${ }^{4}$ Fitz; D.; Reiner, H.; Rode, B. D Pure Appl. Chem. 2007, 79, 2101. [CrossRef]

${ }^{5}$ Saladino, R.; Crestini, C.; Pino S.; Costanzo, G.; Mauro, E. Phys. Life Rev. 2011, 9, 84. [CrossRef] [PubMed]

${ }^{6}$ Andrulis, E. D. Life 2012, 2, 1. [CrossRef]

7 Joyce, G. Nature 1989, 338, 217. [CrossRef] [PubMed]

${ }^{8}$ Maruel, M. C. J. Evol. Biol. 1992, 5, 173. [CrossRef] [PubMed]

${ }^{9}$ Ban, N.; Nissen P.; Hansen J.; Moore P. B.; Seitz T. A. Science 2000, 289, 905. [CrossRef] [PubMed]

${ }^{10}$ Fitz; D.; Jakschitz, T.; Rode, B. M. Em Origins of Life: The Primal Self-Organization; Egel, R.; Lankenau, D. H.; Malkidjanian, A. Y., eds.; Springer: Berlim, 2011, cap. 5.

${ }^{11}$ Joyce, G. F.; Schwartz A. W.; Miller, S. L.; Orgel, L. E. Proc. Natl. Acad. Sci. U. S. A. 1987, 84, 4398. [CrossRef]

12 Eschenmoser, A.; Science 1999, 284, 2118. [CrossRef] [PubMed]

${ }^{13}$ Fishkis, M. Orig. Life Evol. Biosph. 2007, 37, 537. [CrossRef] [PubMed]

${ }^{14}$ Dyson, F. J. J. Mol. Evol. 1982, 18, 344. [CrossRef] [PubMed]

${ }^{15}$ Kauffman, S. J. Theor Biol 1986, 119, 1. [CrossRef]
${ }^{16}$ Dyson, F.; Origins of Life; 5a. ed., Cambridge University Press: Cambridge, 1999.

${ }^{17}$ Brack, A.; Barbier, B. Orig. Life Evol. Biosph. 1990, 20, 139. [CrossRef] [PubMed]

${ }^{18}$ Lahav, N. J. Theor. Biol. 1991, 151, 531. [CrossRef]

${ }^{19}$ Zhao, Y. F.; Cao, P. S. J. Biol. Phys. 1994, 20, 283. [CrossRef]

${ }^{20}$ Zhou, W. H.; Ju, Y.; Zhao, Y. F. Orig. Life Evol. Biosph. 1996, 26, 547. [CrossRef] [PubMed]

${ }^{21}$ Cheng, C. M.; Liu, X. H.; Li, Y. M.; Ma, Y.; Tan, B.; Wan, R.; Zhao, Y. F. Orig. Life Evol. Biosph. 2004, 34, 455. [CrossRef] [PubMed]

${ }^{22}$ Morrison, D. Astrobiology 2001, 1, 3. [CrossRef] [PubMed]

${ }^{23}$ Nasa Astrobiology Institute. Disponível em: $<$

http://astrobiology.nasa.gov/articles/brazilia n-astrobiology-group-joins-nai>. Acessado em: 15 Julho 2012.

${ }^{24}$ Rodrigues, F.; Galante, D.; Paulino-Limas, I. G.; Duarte, R. T. D.; Fiança, A. C. S.; Lange, C.; Janot-Pacheco, E.; Teixeira, R.; Horvath, J. E. Int. J. Astrobiology 2012, 11, 189. [CrossRef] ${ }^{25}$ Harada, K.; Fox, S. W. J. Am. Chem. Soc. 1960, 82, 3745. [CrossRef]

${ }^{26}$ Andini, S.; Benedetti, E.; Ferrara, L.; Paolillo, L. Temussi, P. A. Orig. Life Evol. Biosph. 1975, 6, 147. [CrossRef] [PubMed]

${ }^{27}$ Flores, J. J.; Leckie, J. O. Nature 1973, 244, 435. [CrossRef] [PubMed]

${ }^{28}$ Chung, N.; Lohrmann, R.; Orgel, L. E.; Rabinowitz, J. Tetrahedron 1971, 27, 1205. [CrossRef]

${ }^{29}$ Steinman, G.; Cole, M. N. Proc. Natl. Acad. Sci. U. S. A. 1967, 58, 735. [CrossRef] [PubMed]

${ }^{30}$ Wächtershäuser, G. Pure Appl. Chem. 1993, 65, 1343. [CrossRef]

${ }^{31}$ Huber, C.; Wächtershäuser, G. Science 1998, 281, 670. [CrossRef] [PubMed]

32 Lahav, N.; White, D.; Chang, S. Science 1978, 201, 67. [CrossRef] [PubMed]

33 Bernal, J. D. Proc. Phys. Soc. B 1949, 62, 597. [CrossRef]

${ }^{34}$ Zaia, D. A. M. Amino Acids 2004, 27, 113. [PubMed] 
${ }^{35}$ Lambert, J. F. Orig. Life Evol. Biosph. 2008, 38, 211. [CrossRef] [PubMed]

${ }^{36}$ Mendoza, A. N.; Bernal, A. R.; Mosqueira, F. G. Int. J. Astrobiology 2004, 3, 295. [CrossRef]

37 Flores, J. J.; Bonner, W. A. J. Mol. Evol. 1974, 3, 49. [CrossRef] [PubMed]

38 Bujdák, J.; Faybíková, K.; Eder, A.; Yongyai, Y.; Rode, B. M. Orig. Life Evol. Biosph. 1995, 25, 431. [CrossRef]

39 Basiuk, V. A.; Gromovoy, T. Y.; Golovaty, V. G.; Glukhoy, A. M. Orig. Life Evol. Biosph. 1990, 20, 483. [CrossRef]

40 Bujdák, J.; Rode, B. M. J. Therm. Anal. Calorim. 2003, 73, 797. [CrossRef]

${ }^{41}$ Shanker, U.; Brushan, B.; Bhattacharjee, G.; Kamaluddin Orig. Life Evol. Biosph. 2012, 42, 31. [CrossRef] [PubMed]

42 Pant, C. K.; Lata, H.; Pathak, H. D.; Mehata, M. S. Inter. J. Astrobiology 2009, 8, 107. [CrossRef]

${ }^{43}$ Leyton, P.; Zárate, R.A.; Fuentes, S.; Paipa, C.; Gómez-Jeria, J. S.; Leyton, Y. Byosystem 2011, 104, 118. [CrossRef] [PubMed]

${ }^{44}$ Schwendiger, M. G.; Rode, B. M. Anal. Sci. 1989, 5, 411. [CrossRef]

${ }^{45}$ Schwendiger, M. G.; Tauler, R.; Saetia, S.; Liedl, K. R.; Kroemer, R. T.; Rode, B. M. Inorg. Chim. Acta 1995, 228, 207. [CrossRef]

${ }^{46}$ Carver, J. H. Nature 1981, 292, 136. [CrossRef]

47 Plankensteiner, K.; Reiner, H.; Rode, D. M. Mol. Divers. 2006, 10, 3. [CrossRef] [PubMed] ${ }^{48}$ Rode, M. B.; Son, H. L.; Suwannachot, Y. Orig. Life Evol. Biosph. 1999, 29, 273. [CrossRef] [PubMed]

${ }^{49}$ Rode, B. M. Peptides 1999, 20, 773. [CrossRef]

${ }^{50}$ White, D. H.; Erickson, C. J. J. Mol. Evol. 1980, 16, 279. [CrossRef] [PubMed]

51 Suwannachot, Y.; Rode, B. M. Orig. Life Evol. Biosph. 1998, 28, 79. [CrossRef] [PubMed]

52 Gorlero, M.; Wieczorek, R.; Adamala, K.; Giorgi, A.; Shininà, M. E.; Stano, P.; Luisi, P. L. FEBS Lett. 2009, 583, 153. [CrossRef] [PubMed]
${ }^{53}$ Lee, D. H. L.; Granja, J. R.; Martinez, J. A; Severin, K.; Ghadiri, R. Nature 1996, 382, 525. [CrossRef] [PubMed]

${ }^{54}$ Luisi, P. L.; Walde, P.; Oberholzer, T. Curr. Opin. Collid. Interface Sci. 1999, 4, 33. [CrossRef]

${ }^{55}$ Chen, I. A.; Walde, P. Em The Origins of Life, Deamer, D.; Szostak, J. K, eds.; Cold Spring Harbor Laboratory Press, 2010 [CrossRef]

${ }^{56}$ Carny, O.; Gazit, E. Orig. Life Evol. Biosph. 2011, 41, 121. [CrossRef] [PubMed]

${ }^{57}$ Hauser, C. A.; Deng, R.; Mishra, A.; Loo, Y.; Khoe, U.; Zhuang, F.; Cheong, D. W.; Accardo, A.; Sullivan, M. B.; Riekel, C.; Ying, J. Y.; Hauser, U. A. Proc. Natl. Acad. Sci. U. S. A. 2011, 108, 1361. [CrossRef] [PubMed] ${ }^{58}$ Gazit, E. Prion 2007, 1, 32. [CrossRef] [PubMed]

${ }^{59}$ Monnard, P. A.; Deamer, D.W.; Orig. Life Evol. Biosph. 2001, 31, 147. [CrossRef] [PubMed]

${ }^{60}$ Ohad, C.; Gazit, E. Orig. Life Evol. Biosph. 2011, 41, 121. [CrossRef] [PubMed]

${ }^{61}$ Dadalti, P.; Goodheart, C. Med. Hypotheses 2007, 69, 724. [CrossRef] [PubMed]

62 Maury, C. P. J. Orig. Life Evol. Biosph. 2009, 39, 141. [CrossRef] [PubMed]

${ }^{63}$ Fishkis, M. Orig. Life Evol. Biosph. 2011, 41, 261. [CrossRef] [PubMed]

${ }^{64}$ Gleiser, M.; Thorarinson, J.; Walker, S. I. Orig. Life Evol. Biosph. 2008, 38, 499. [CrossRef] [PubMed]

${ }^{65}$ Islas, R. J.; Micheau, J.; Buhse, T. Orig. Life Evol. Biosph. 2004, 34, 497. [CrossRef] [PubMed]

${ }^{66}$ Weber, A. L.; Pizzarello, S. Proc. Natl. Acad. Sci. 2006, 103, 12713. [CrossRef] [PubMed]

${ }^{67}$ Fitz, D.; Jakschitz, T.; Rode, B. M. J. Inorg. Biochem. 2008, 102, 2097. [CrossRef] [PubMed]

${ }^{68}$ Plankensteiner, K.; Reiner, H.; Rode, B. M.; Orig. Life Evol. Biosph. 2005, 35, 411. [CrossRef] [PubMed]

${ }^{69}$ Rode, B. M. Peptides 1999, 20, 773. [CrossRef] 